\title{
Strukturbiologie
}

\section{Die Coronavirus Structural Task Force}

\author{
ANDREA THORN
}

RUDOLF-VIRCHOW-ZENTRUM - CENTER FOR INTEGRATIVE AND TRANSLATIONAL BIOIMAGING, UNIVERSITÄT WÜRZBURG

DOI: $10.1007 / \mathrm{s} 12268-020-1408-0$

(C) Die Autorin 2020

Die moderne Biochemie ist ohne die genaue Kenntnis von Molekülstrukturen nicht vorstellbar: Protein-, RNA- und DNAStrukturen ermöglichen uns Erkenntnisse über die chemischen Abläufe in lebenden Zellen. Über 160.000 bekannte Strukturen bilden den Schlüssel zu unserem Verständnis des Lebens.

Es gibt allerdings ein fundamentales Problem in der Strukturbiologie: Die dreidimensionalen Strukturen von Molekülen werden nicht direkt gemessen, sondern die Messdaten aus NMR (nuclear magnetic resonance), Kristallographie oder Kryo-Elektronenmikroskopie (Kryo-EM) müssen erst prozessiert und anschließend mit einem Strukturmodell interpretiert werden. Doch diese Modelle passen nie perfekt zu den Messdaten: Die Diskrepanz zwischen Modell und Messung wird z. B. in der Kristallographie als R-Wert in Prozent angegeben. Während Kleinmoleküle typischerweise Werte von fünf Prozent erreichen, sind es bei biologischen Makromolekülen 20-25 Prozent [1]. Diese verhältnismäßig schlechte Übereinstimmung macht es oft unmöglich, alle biologischen Fragen zu beantworten, und kann sogar die ganze Strukturlösung verfälschen. Das ist - zusammen mit der Komplexität von Strukturaufklärungen - der Grund, warum Fehler auch bei sorgfältiger Arbeit oft nicht zu vermeiden sind. Um Lösungen für diese Probleme zu finden, entwickelt meine Arbeitsgruppe an der Universität Würzburg neue Methoden: Wie können wir die Diskrepanz verringern und Strukturen besser modellieren? Wie können wir die Fehler in Messdaten, z. B. in der Kristallographie oder Kryo-EM, erkennen und reduzieren? Dank immer robusterer Methoden sind wir mittlerweile in der Lage, selbst schwierige, schlecht aufgelöste Strukturen großer Komplexe zu bestimmen.

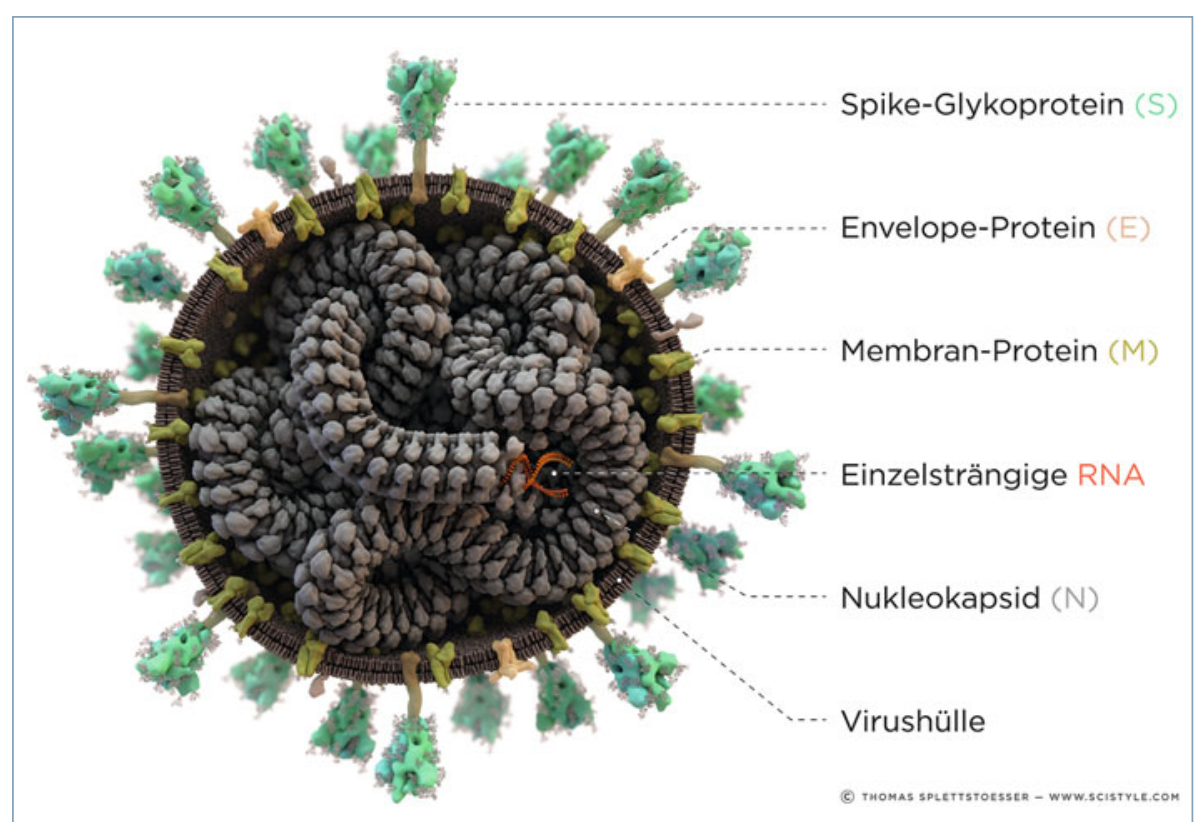

$\Delta$ Abb. 1: Abbildung des Coronavirus SARS-CoV-2 mit verschiedenen Proteinstrukturen. Nach Infektion der Wirtszelle bildet der Virus zusätzlich viele weitere Proteine, um sich zu replizieren. Bild: Thomas Splettstößer/SciStyle.com.

\section{Fehlerhafte Strukturen von SARS-CoV-2}

Das Coronavirus SARS-CoV-2 hat die Welt gerade fest im Griff, und Proteinstrukturen spielen bei seiner Erforschung eine wichtige Rolle. Sie können Aufschluss über seinen Infektionszyklus geben und die gezielte Störung einzelner Coronavirus-Proteine durch strukturbasiertes Wirkstoffdesign ermöglichen. In den letzten Monaten hat die strukturbiologische Community schnell und umfassend reagiert und konnte viel zu unserem Wissen über das neue Coronavirus beitragen. Von 16 der 28 Proteine im Genom von SARS-CoV und SARS-CoV-2 gibt es mittlerweile (Teil-)Strukturen, insgesamt über 500 Strukturmodelle in der Proteindatenbank (PDB) [2]. Doch der hohe Zeitdruck fordert seinen Preis: Die Strukturen, die oft noch vor der Veröffentlichung in der PDB zur Verfügung gestellt werden, enthalten besonders viele Fehler.

Im Januar dieses Jahres habe ich zum ersten Mal makromolekulare Strukturen aus dem Coronavirus analysiert und festgestellt, dass diese mit heutigen Methoden wesentlich verbessert werden können. Zu diesem Zeitpunkt begannen viele Arbeitskreise weltweit gerade, nach Ansatzpunkten für die Entwicklung eines Wirkstoffes zu suchen. Ich brachte ein Team aus Methodenentwicklern und Studenten zusammen, um die Molekülstrukturen aus SARS-CoV und SARS-CoV-2 systematisch zu überprüfen und, wo möglich, zu verbessern. Wir fanden Probleme bei der Messung, wie Kontaminationen mit Eisstreuung, Strahlenschäden und fehlende Reflexe in kristallographischen Datensätzen, sowie Fehler in den Modellen, z. B. um bis zu neun Aminosäurereste verschobene Sequenzen in KryoEM-Strukturen, zu viele Ramachandran-Ausreißer in NMR-Strukturen, umgedrehte glykosidische Zucker und falsche Liganden. Jedes Mal, wenn wir eine Struktur verbessern können, stellen wir den Autoren das neue Strukturmodell zur Verfügung. Zudem sind die Daten auf unserer Seite insidecorona.net 
frei zugänglich, wo wir auch Hintergründe zur Funktion der Strukturen erklären.

\section{Daten für die internationale Forschung}

Wir erhielten nach und nach Anfragen von Arzneimittelentwicklern überall auf der Welt. Unsere Daten werden als Grundlage für Molekulardynamikberechnungen von Folding@home [3] auf 1,4 Millionen Heimrechnern verwendet, in der EU-Initiative JEDI COVID-19 [4] zur Erforschung eines möglichen Arzneimittels, und sie sind in der Datenbank des MolSSI [5] integriert. Die Coronavirus Structural Task Force hat mittlerweile 18 Mitglieder aus sechs Ländern.

Jede Woche erscheinen neue Strukturen in der PDB. Unser Ziel ist es, dafür zu sorgen, dass sie so gut wie möglich sind. Dann stellen wir sie der internationalen Forschungsgemeinschaft zur Verfügung und leisten so unseren Beitrag zum Kampf gegen COVID-19.

\section{Literatur}

[1] Holton JM, Classen S, Frankel KA et al. (2014) The R-factor gap in macromolecular crystallography: an untapped potential for insights on accurate structures. FEBS J 281:4046-4060

[2] Berman HM, Westbrook J, Feng Z et al. (2000) The Protein Data Bank. Nucleic Acids Res 28:235-242

[3] Shirts M, Pande VS (2000) Screen savers of the World Unite! Science 290:1903-1904

[4] Joint European Disruptive Initiative (JEDI), https://www.covid19.jedi.group

[5] The Molecular Sciences Software Institute (MolSSI), https://covid.molssi.org

Funding: Open access funding durch das Bundesministerium für Bildung und Funding: Open access funding durch das Bundesministerium fur
Forschung (Grant Number: 05K 19WWA, Grant Acronym: AUSPEX).

Open Access: Dieser Artikel wird unter der Creative Commons Namensnennung 4.0 International Lizenz veröffentlicht, welche die Nutzung, Vervielfältigung,

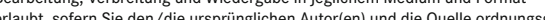
mäß nennen, einen Link zur Creative Commons Lizenz beifügen und angeben, ob Änderungen vorgenommen wurden. Die in diesem Artikel enthaltenen Bilder und sonstiges Drittmaterial unterliegen ebenfalls der genannten Creative Commons Lizenz, sofern sich aus der Abbildungslegende nichts anderes ergibt. Sofern das betreffende Material nicht unter der genannten Creative Commons Lizenz steht und die betreffende Handlung nicht nach gesetzlichen Vorschriften erlaubt ist, ist für die oben aufgeführten Weiterverwendungen des Materials die Einwilligung des jeweiligen Rechteinhabers einzuholen. Weitere Details zur Lizenz entnehmen Sie bitte der Lizenzinformation auf http://creativecommons.org/licenses/ by $/ 4.0 /$ deed.de

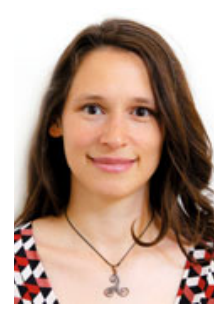

Korrespondenzadresse:

Dr. Andrea Thorn Rudolf-Virchow-Zentrum Universität Würzburg Josef-Schneider-Straße 2, Haus D 15 D-97080 Würzburg andrea.thorn@web.de www.thorn-lab.de 